\title{
The Impact of Road Accidents on Brain Injury
}

\author{
Mohsen Ansari' Leyla Bayan², Ali Gorji ${ }^{2,3,4^{*}}$ \\ ${ }^{1}$ Police University, Tehran, Iran \\ ${ }^{2}$ Shefa Neuroscience Research Center, Khatam Alanbia Hospital, Tehran, Iran \\ ${ }^{3}$ Mashhad Neuroscience Department, Mashhad University of Medical Sciences, Mashhad, Iran \\ ${ }^{4}$ Epilepsy Research Center, Department of Neurology and Neurosurgery, Westfälische Wilhelms-Universität Münster, Münster, Germany
}

\section{A BSTRACT}

Introduction: Brain injuries occur as a result of sudden and severe collision of head to hard object which can be mild, moderate, or severe. Epilepsy, persistent headaches, brain hemorrhage, infection, stroke, dementia, mental retardation, brain death, psychological and mood disorders as well as hormonal disorders are the consequences of brain injuries which sometimes remain persistent throughout the whole life. The leading causes of traumatic brain injury are car accidents, falls, physical violence, accidents during work, accidents inside the home, and sport accidents. The most important cause of head trauma in Iran is traffic accidents. Each year more than 700 thousand people injured in road accidents that most of them are suffering from head trauma. Each year several thousand people kill in road accident that imposes a large economic burden on the national healthcare system In Iran. The number of road accidents in Iran is about 20 times more than the global average norm. Each nineteen minutes, one person dies in a traffic accident. Given the high rate of mortalities due to the brain injuries, Shefa Neuroscience Research Center, Khatam Alanbia Hospital affiliated with the Foundation of Martyrs and Veterans Affairs has begun to have some preventive measures on the brain and spinal cord injuries. These activities include holding international congresses, publishing books and brochures as well as holding scientific workshops. The main purpose of holding international road safety congress is to present a plan to prevent the brain injuries which was fulfilled with the cooperation of different national and international organizations during the last five years. Conclusion: Prevention of traffic accidents and improving public knowledge are the main missions for our program. Shefa Neuroscience Research Center is trying to gather responsible groups and organizations during annual international congresses. It is also aimed to decrease the number of accidents using the experiences of leading successful countries.

\section{Key words:}

1. Brain Injuries

2. Accidents, Traffic

3. Congresses

\section{*Corresponding Author: Ali Gorji}

E-mail:Gorjial@uni-muenster.de 


\title{
اثر تصادفات جادهاى بر آسيب مغزى
}

\author{
محسن انصارى'، ليلا بيان'، على كرجى F.r.r.F \\ دانشكاه علوم انتظامى، تهران، ايران \\ 'مركز تحقيقات علوم اعصاب شفا، بيمارستان خاتمالانبياء، تهران، ايران \\ "تروه علوم اعصاب مشهد، دانشعاه علوم يزشكى مشهد، مشهل، ايران \\ †مركز تحقيقات صرع، كروه نورولوزى و جراحى مغز و اعصاب، دانشكاه مونستر، مونستر، آلمان
}

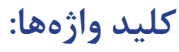

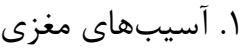

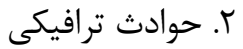

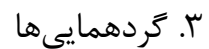

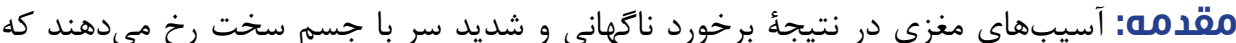

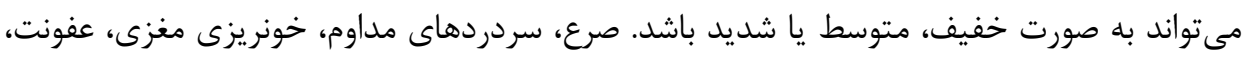

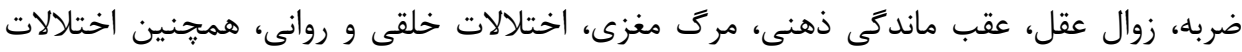

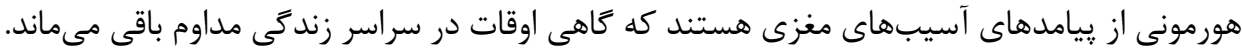

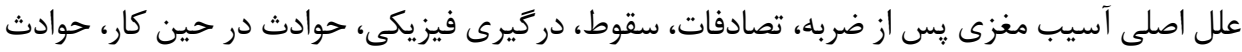

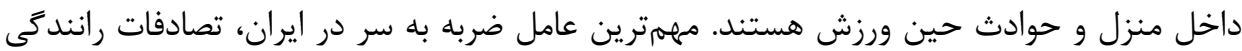

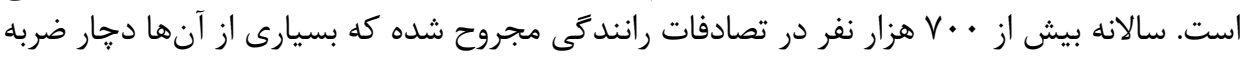

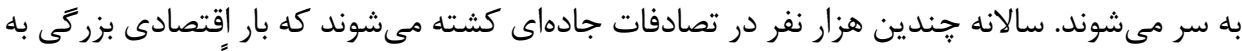

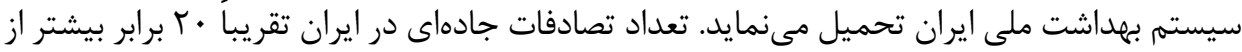

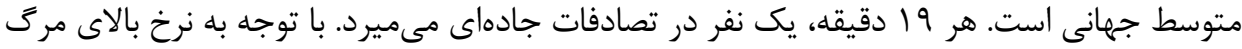

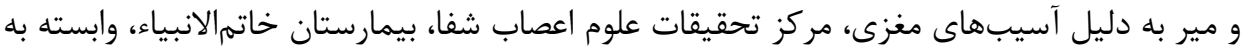

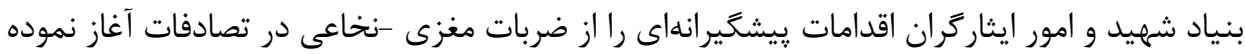

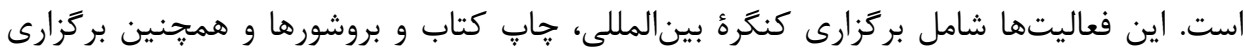

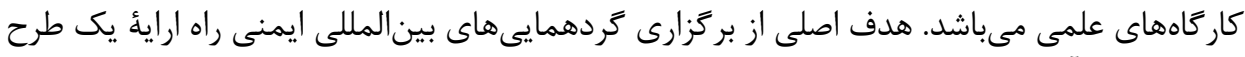

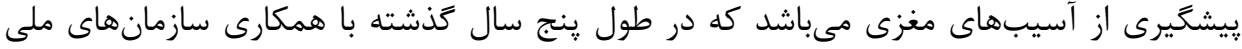

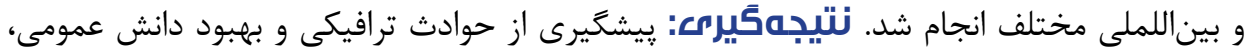

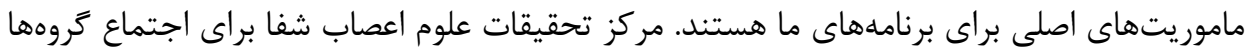

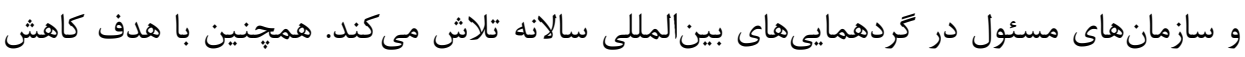

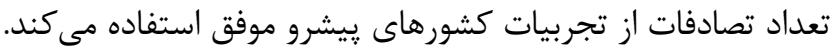

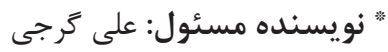

آدرس الكترونيكى: Gorjial@uni-muenster.de 


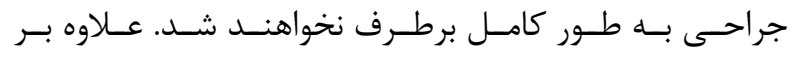

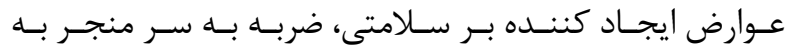

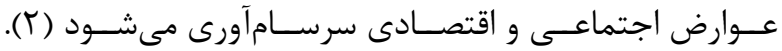

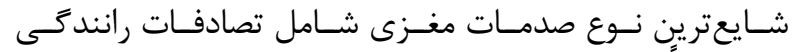

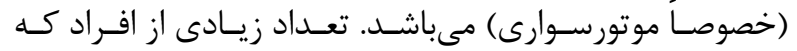

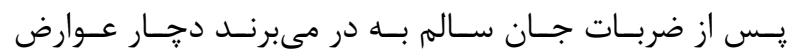

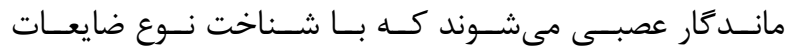

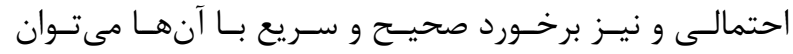

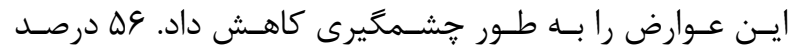

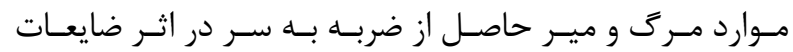

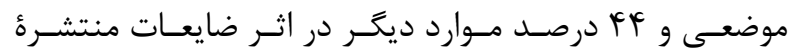

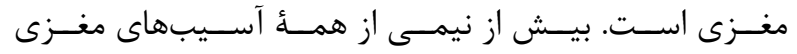

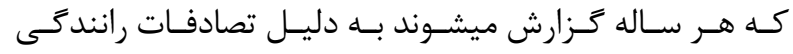

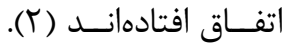

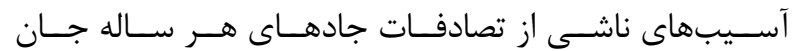

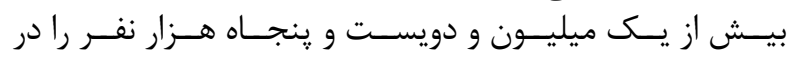

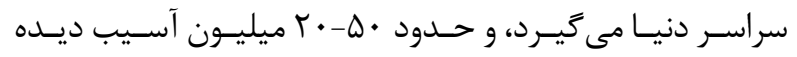

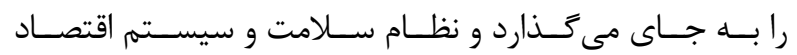

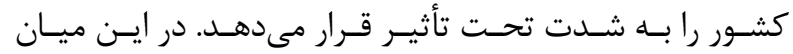

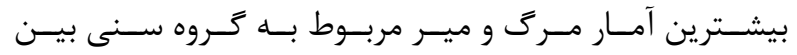

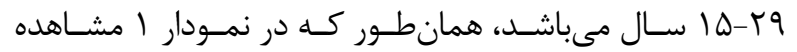

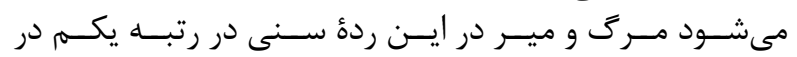

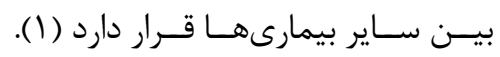

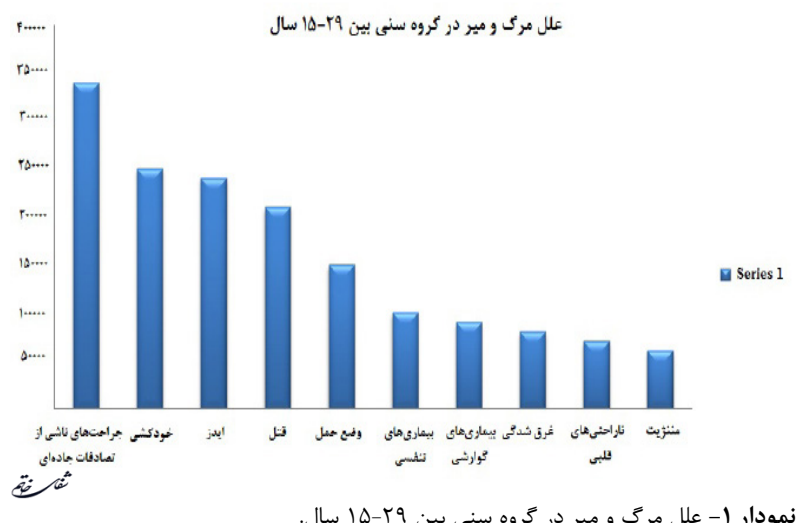

نمودار ا- علل مركى و مير در كروه سنى بين وج-ها سال.

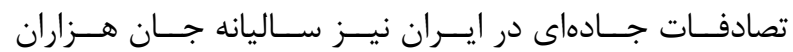

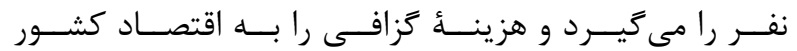

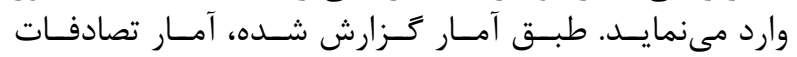

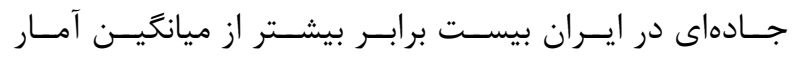

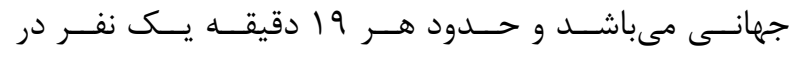

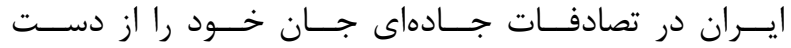

مى مدهــد (r) (r)

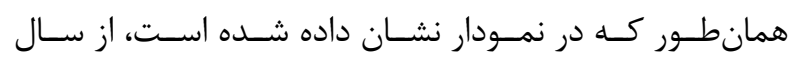

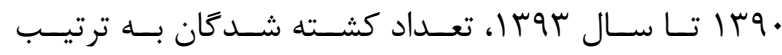

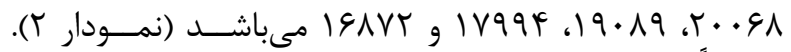
تقريبـاً بيسش از نيمـى از كسـانى كـهـ در تصادفــات جــادهاى
مقدمه

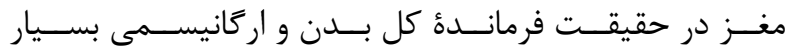

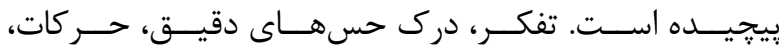

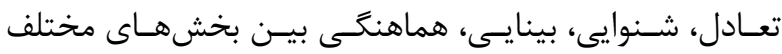

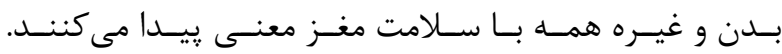

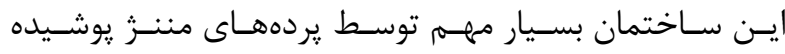

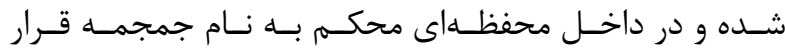

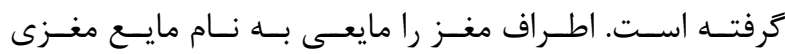

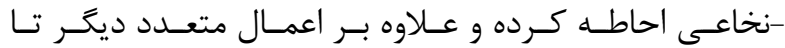

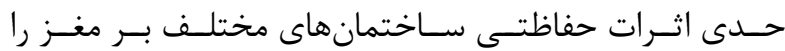

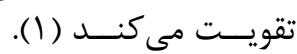

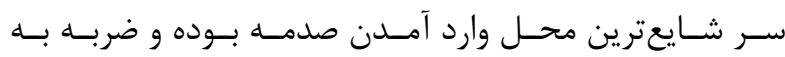

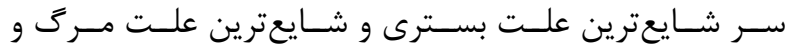

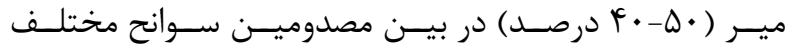

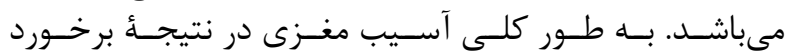

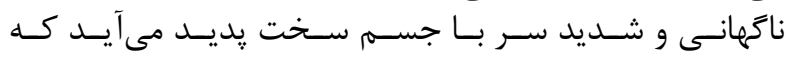

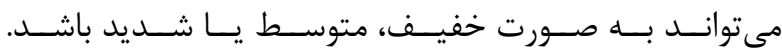

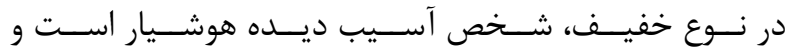

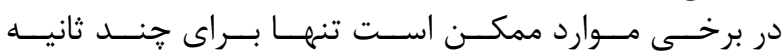

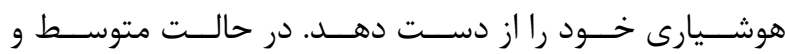

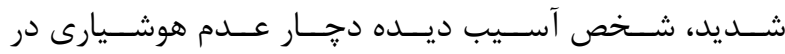

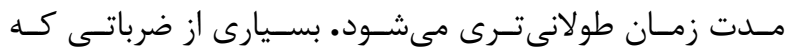

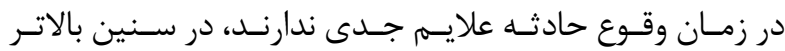

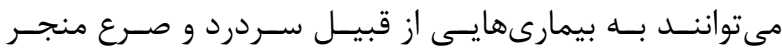

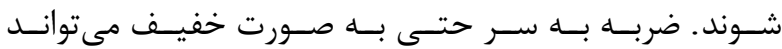

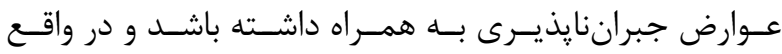

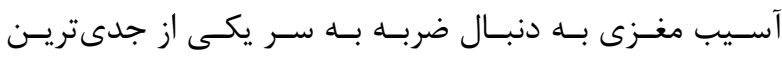

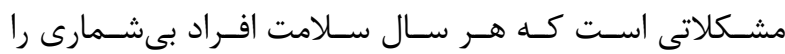

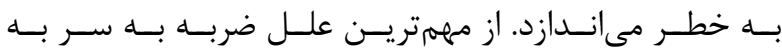

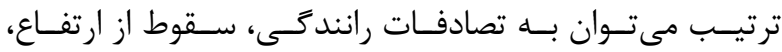

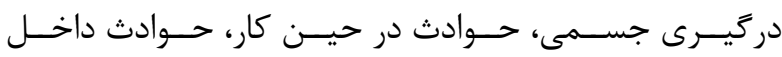

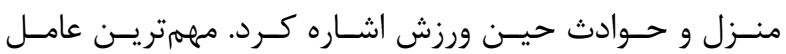

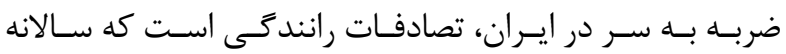

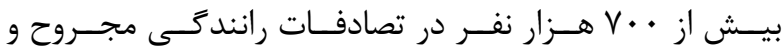

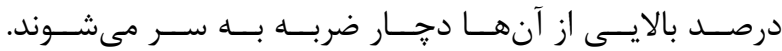

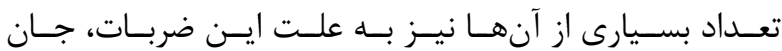

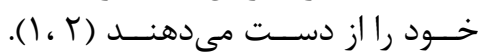

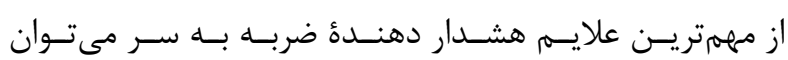

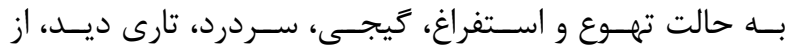

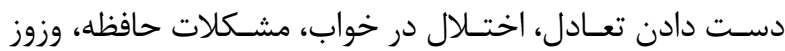

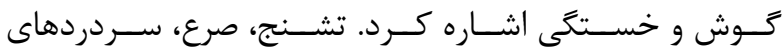

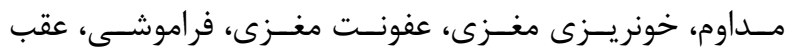

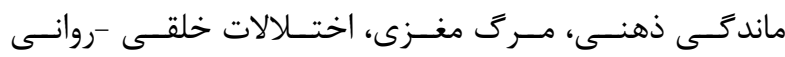

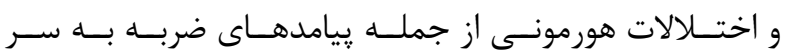

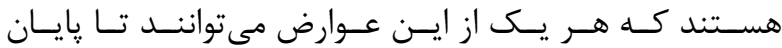

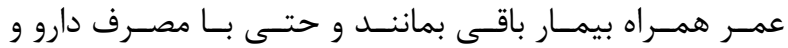




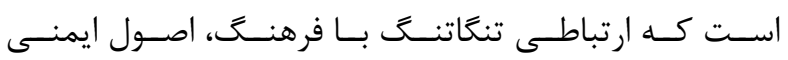

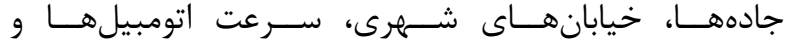

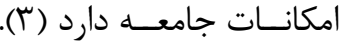

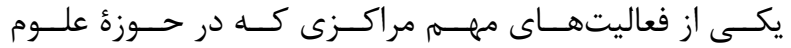

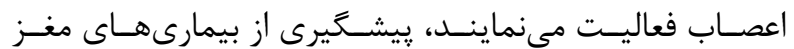

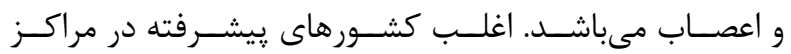

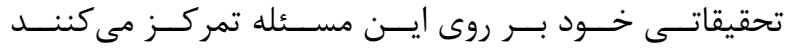

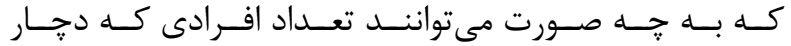

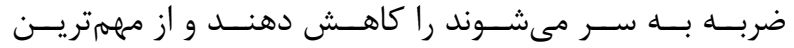

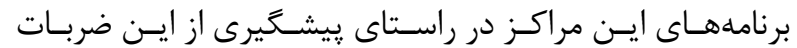

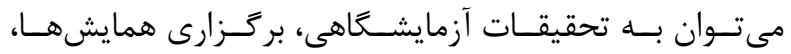

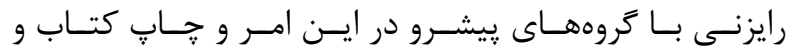

بروشـور اشـاره كـــــ (ه).

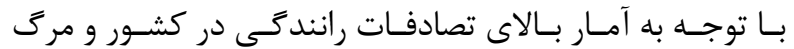

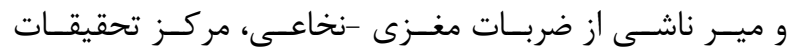

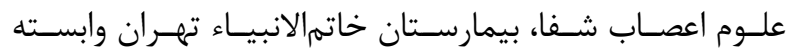

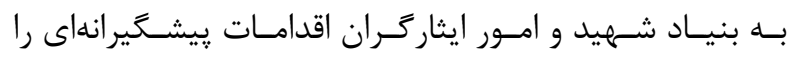

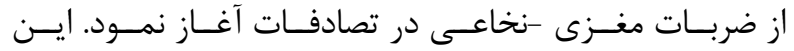

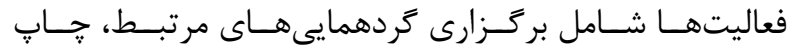

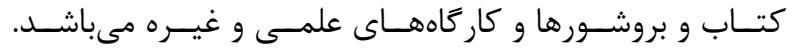

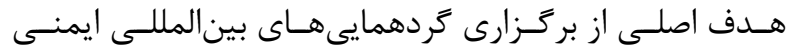

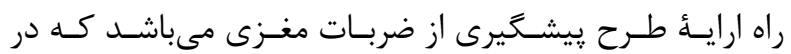

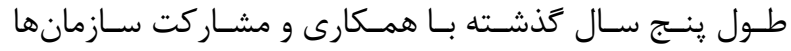

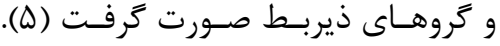

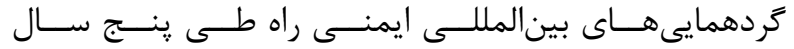

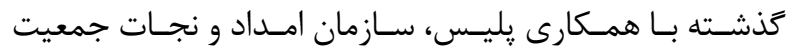

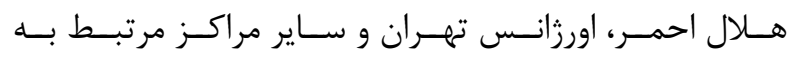

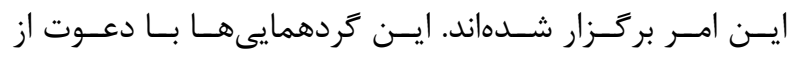

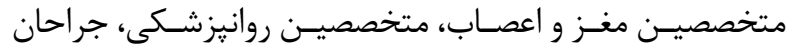

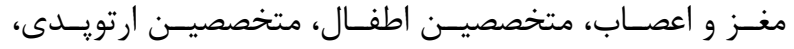
متخصصيـن جراحسى يلاسـتيك، يزشـكان خانـواده، يزشـكان إنـان

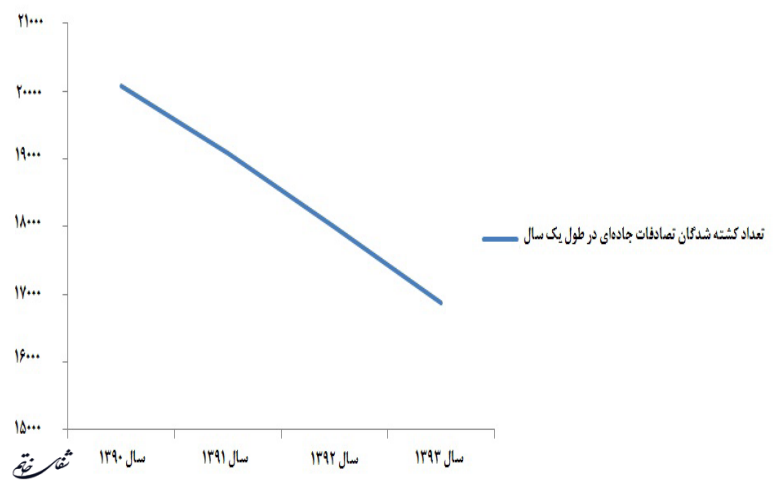

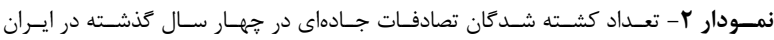

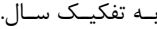

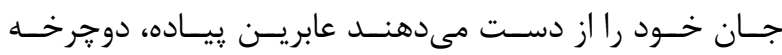

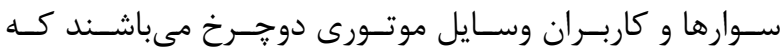

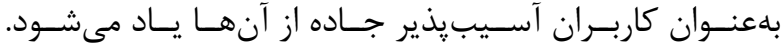

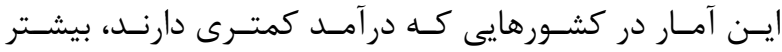

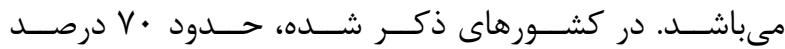

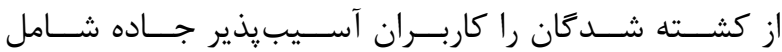

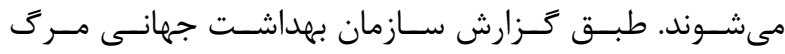

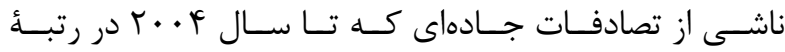

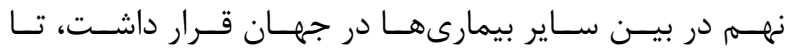

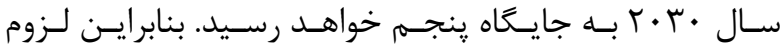

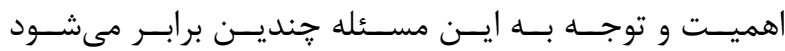

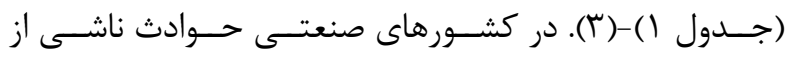

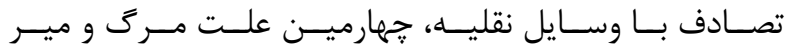

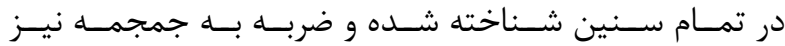

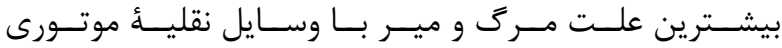

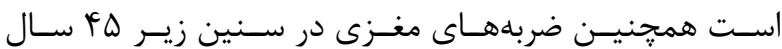

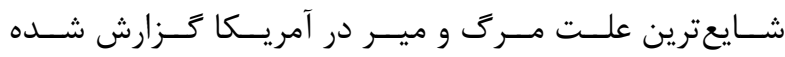

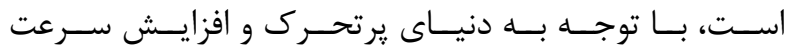

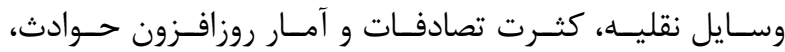

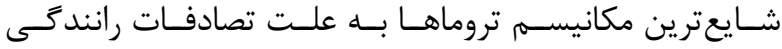

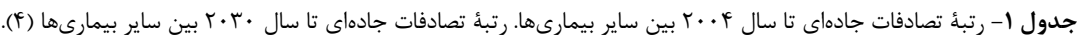

\begin{tabular}{|c|c|c|c|c|c|}
\hline درصد & علت اصلى & رتبه & درصد & علت اصلى & رتبه \\
\hline$I K / Y$ & بيمارى هاى قلبى & 1 & $1 T / r$ & بيمارى هاى قلبى & 1 \\
\hline 9/V & بيمارى هاى مغزى -مروقى & r & १/Y & بيمارى هاى مغزى -عروقى & r \\
\hline$v$ & بيمارى هاى مزمن انسداد ريه & r & r & عفونتهاى تنفسى & r \\
\hline$\Delta / 1$ & عقونتهاى ثنفسى & f & $\Delta / 1$ & بيمارىهاى مزمن انسدادى ريد & f \\
\hline$r / 6$ & جراحت هاى ناشى از تصادفات جاداى & $\Delta$ & $r / 4$ & بيمارى كوارشى & $\Delta$ \\
\hline$r / \Delta$ & سرطانهاى مربوط به سيستم تنفسى & 4 & $r / \Delta$ & ايدز & 8 \\
\hline$r / \Delta$ & ديابت & v & $r / \Delta$ & سل & v \\
\hline$T / 4$ & بيمارى هاى مربوط به فشار خون & $\Lambda$ & $T / r$ & سرطانهاى مربوط به سيستم تنفسى & $\wedge$ \\
\hline t/T & سرطان معده & 9 & $T / T$ & جراحتهاى ناشى از تصادفات جادهاى & 9 \\
\hline 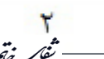 & ايدز & 1 . & $r$ & مرح نوزادان نارس & 1. \\
\hline
\end{tabular}




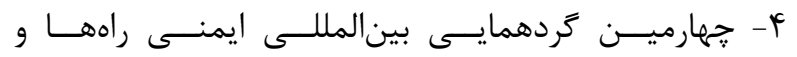

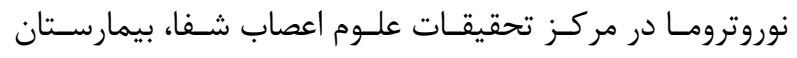

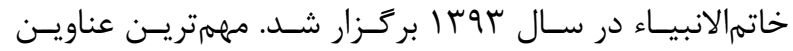

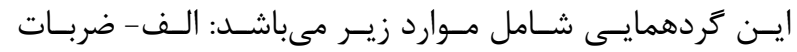

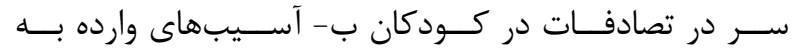

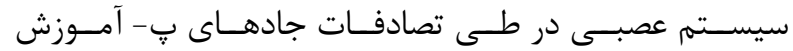

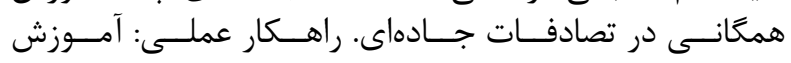

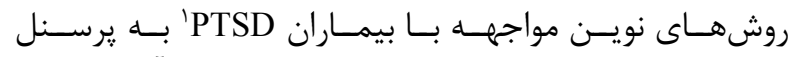

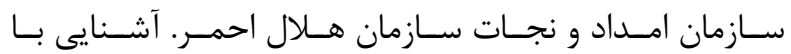

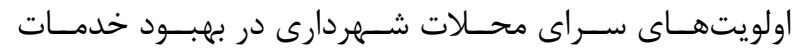

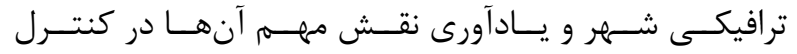

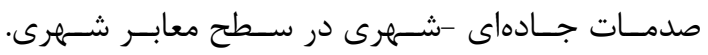

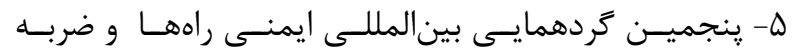

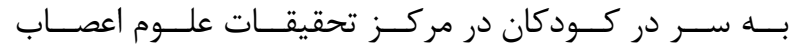

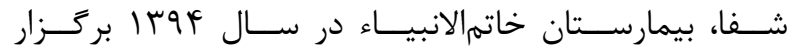

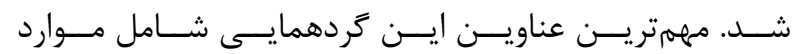

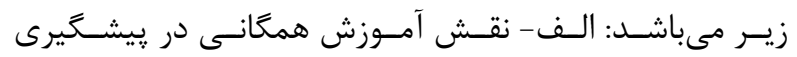

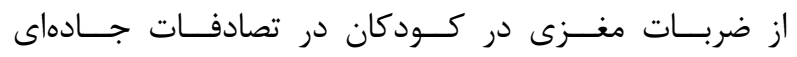

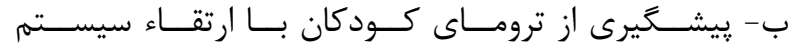

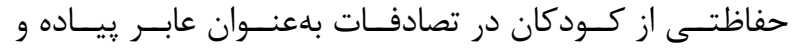

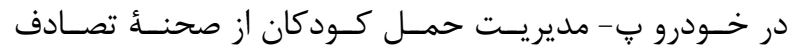

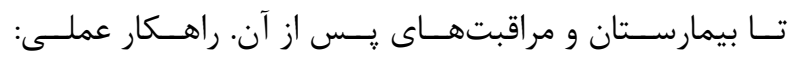

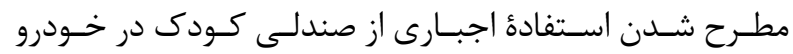

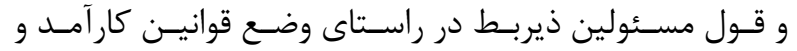

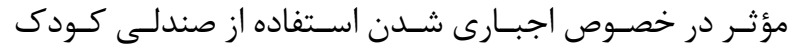

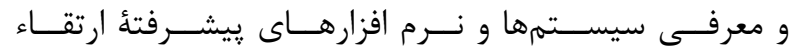

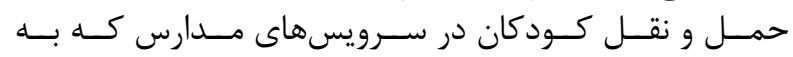

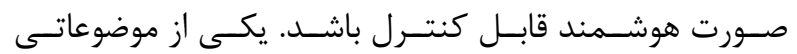

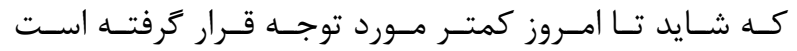

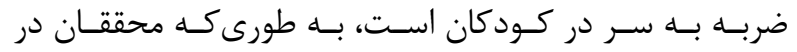

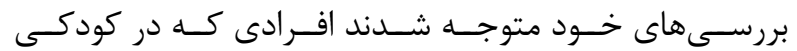

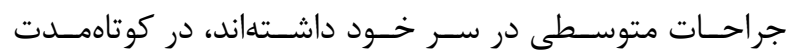

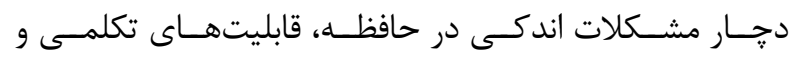
توانايـى تمركــز شـــــاند.

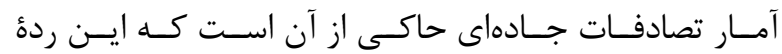

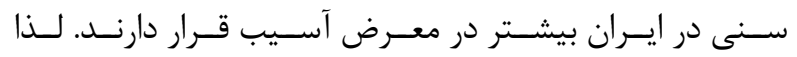

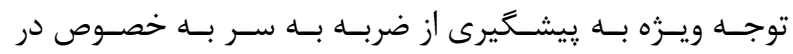

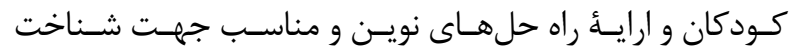

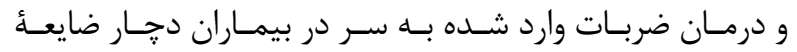

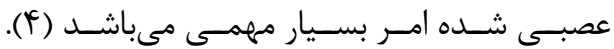

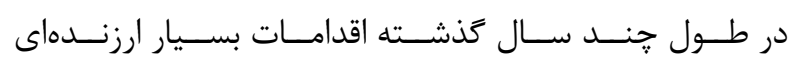

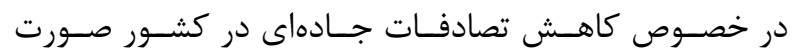

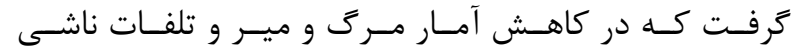

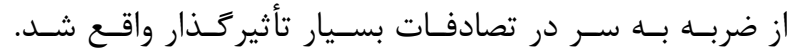

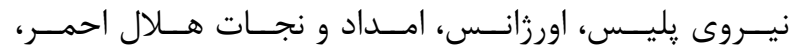

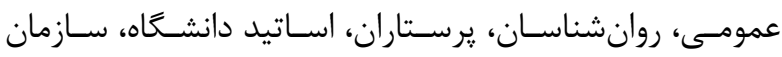

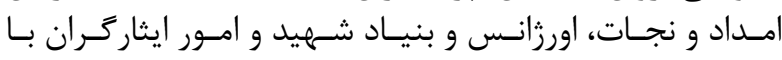

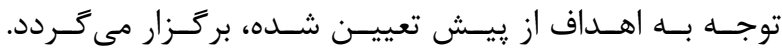

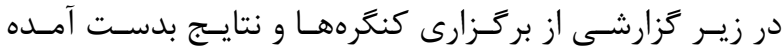

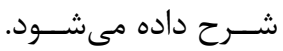

\section{كزارش كنكرهها}

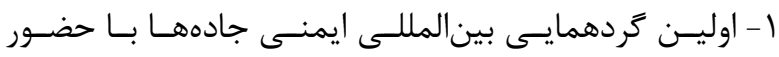

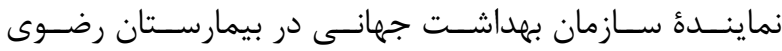

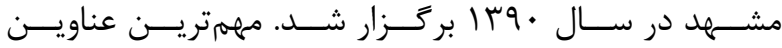

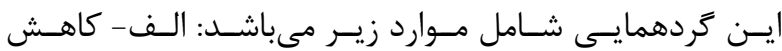

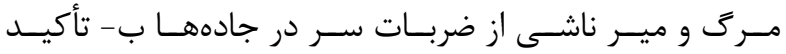

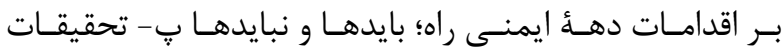

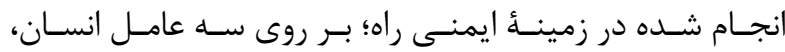

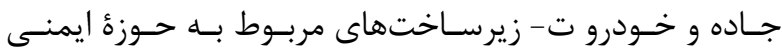

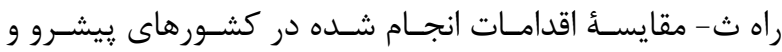

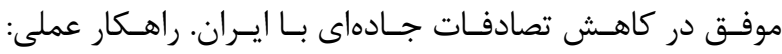

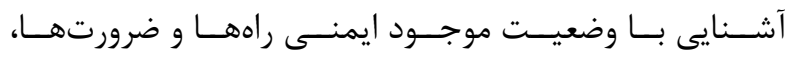

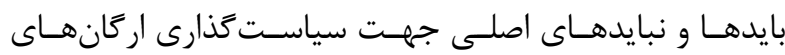

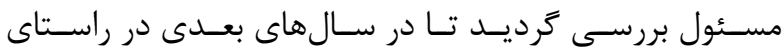

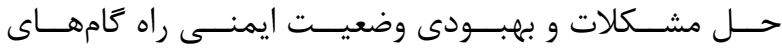
مؤثـــى برداشـته شـود.

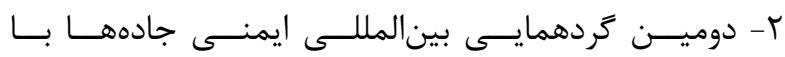

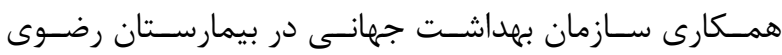

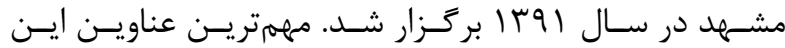

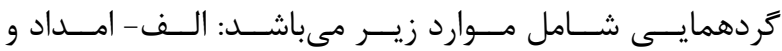

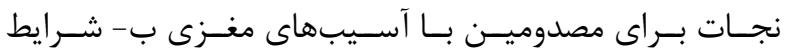

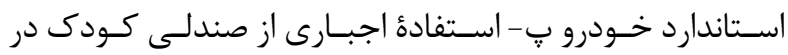

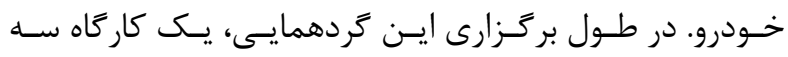

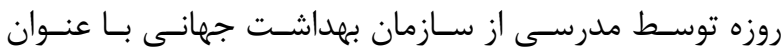

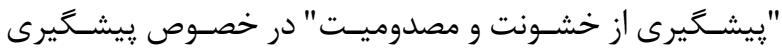

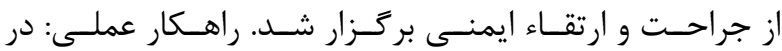

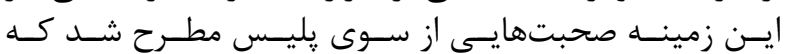

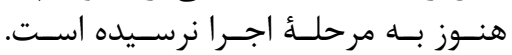

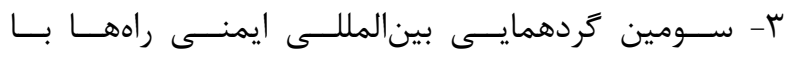

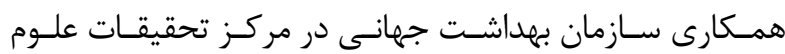

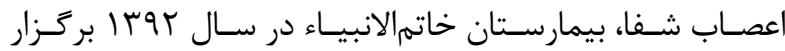

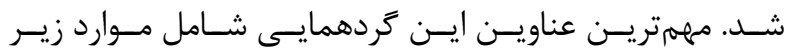

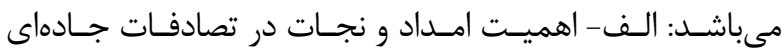

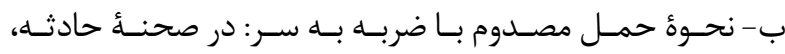

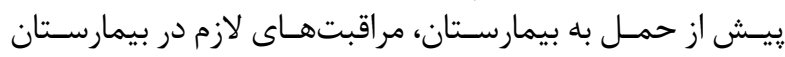

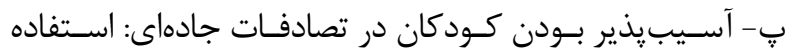

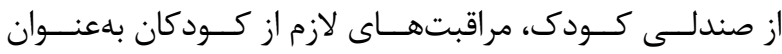

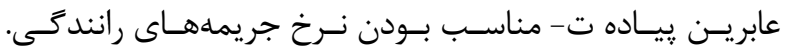

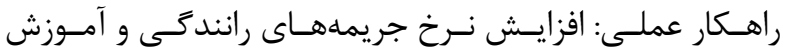
صحيـح انتقـال بيمـار بــهـ بيمارســتان.

${ }^{1}$ Post-traumatic stress disorder 


\begin{tabular}{|c|c|c|}
\hline & \multicolumn{2}{|c|}{ جدول r- كَزارش بركَزارى كنكَرها. } \\
\hline اقداعات صورت كرفته & مهيمترين موضوعات مرتبط با نوروتوروما & \\
\hline 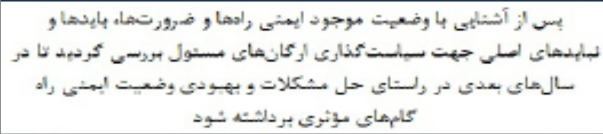 & 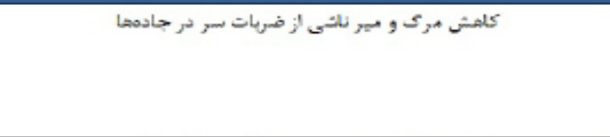 & 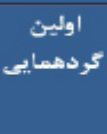 \\
\hline 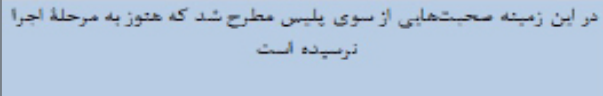 & 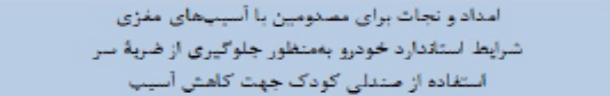 & 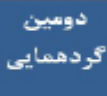 \\
\hline 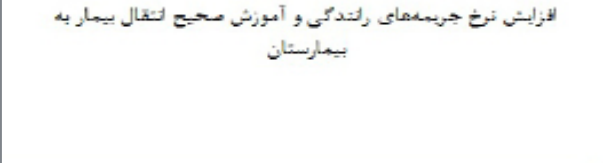 & 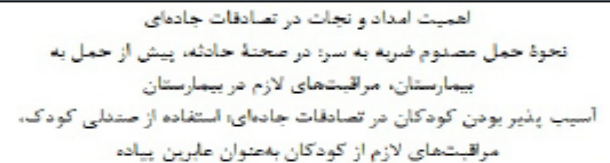 & 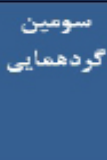 \\
\hline 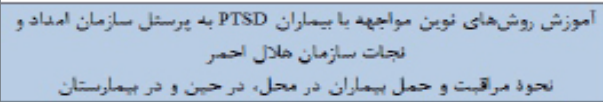 & 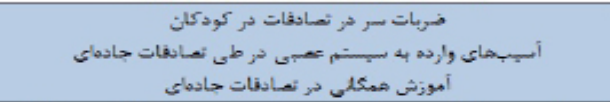 & 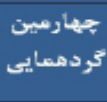 \\
\hline 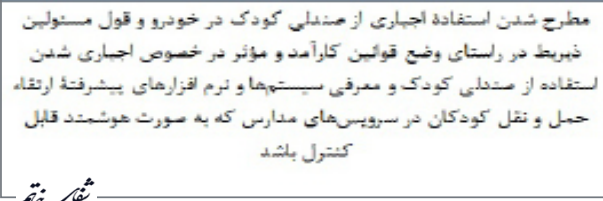 & 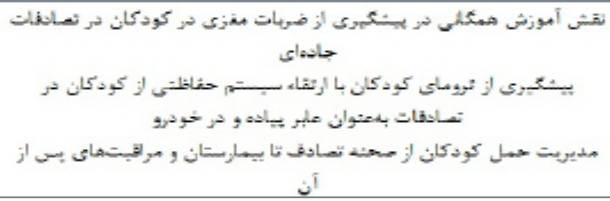 & كردمعايي \\
\hline
\end{tabular}

\section{نتيجه}

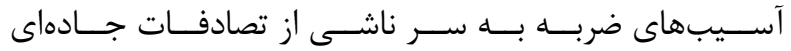

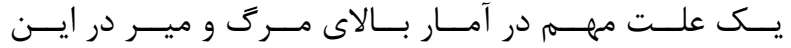

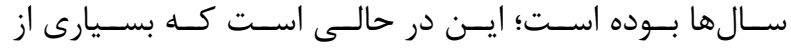

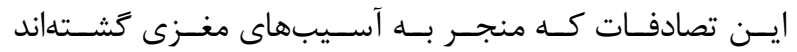

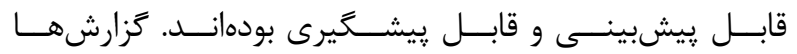

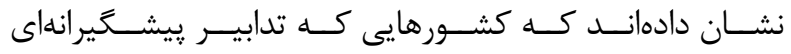

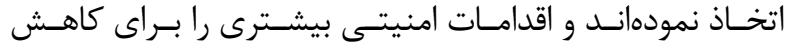

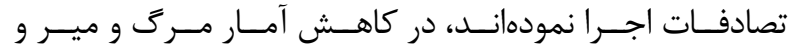

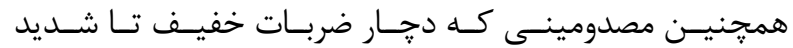

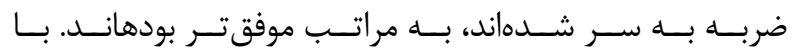

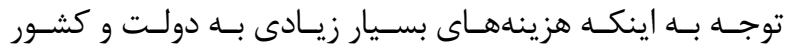

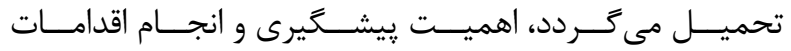

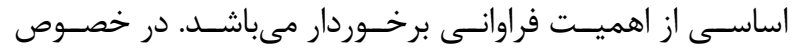

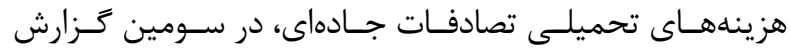

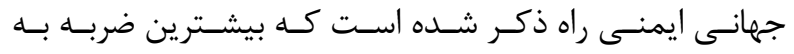

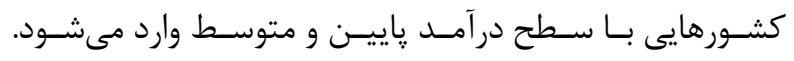

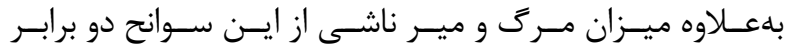

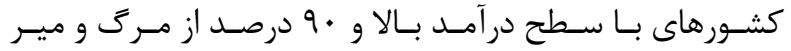

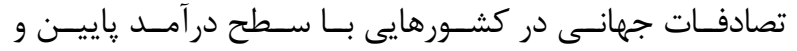

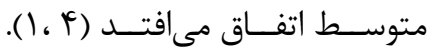

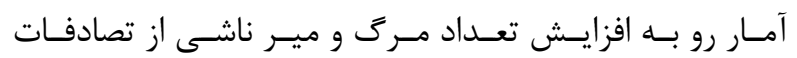

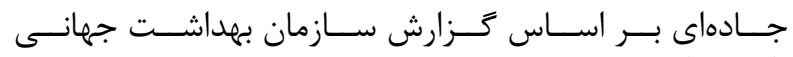

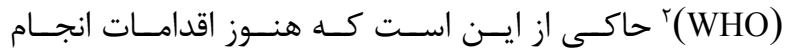

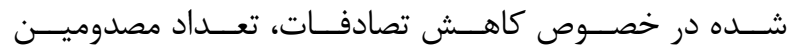

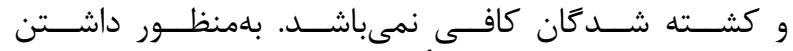

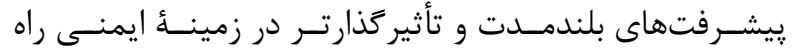

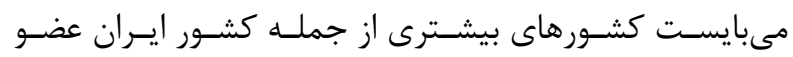

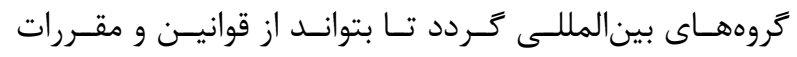

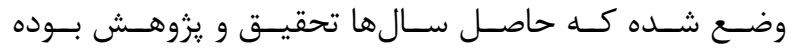

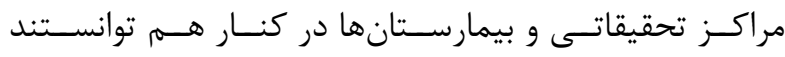

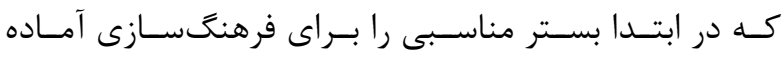

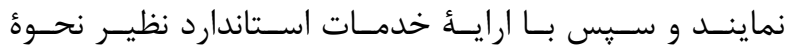

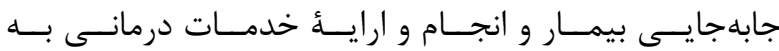

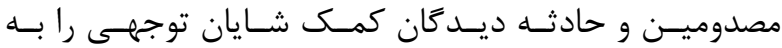

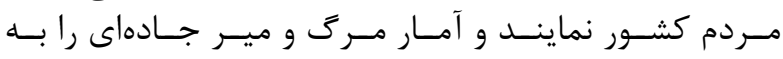

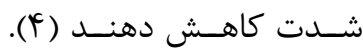

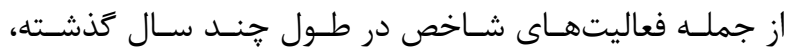

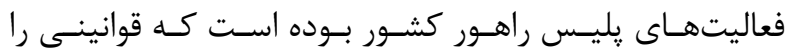

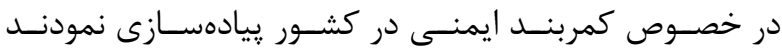

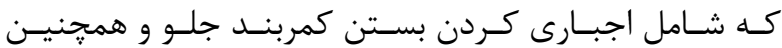

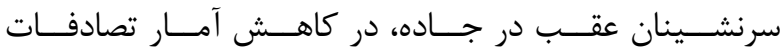

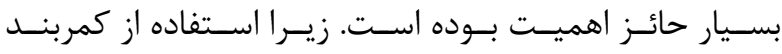

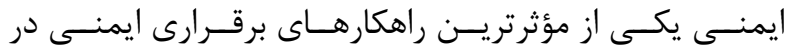

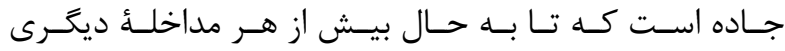

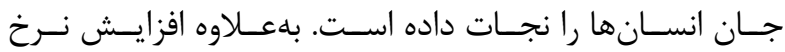

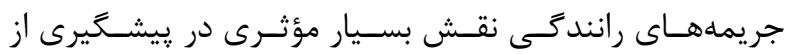

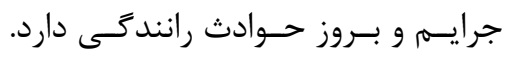

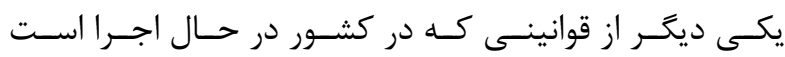

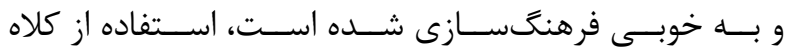

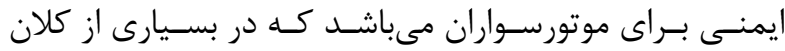

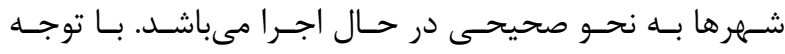

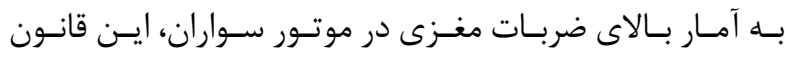

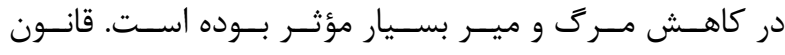

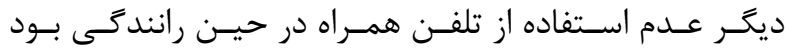

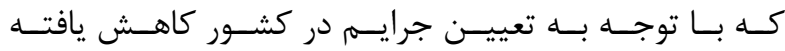

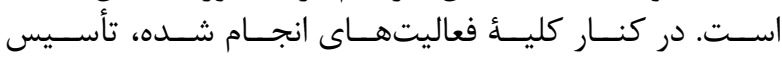

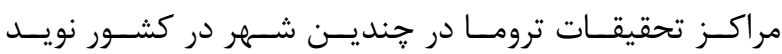

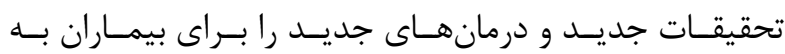

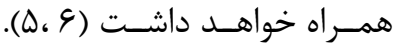

${ }^{2}$ World health organization 


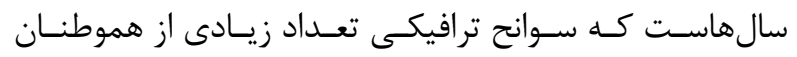

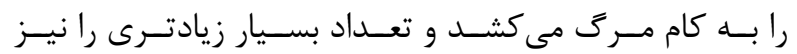

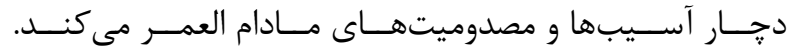

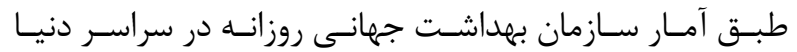

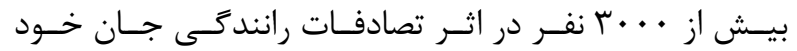

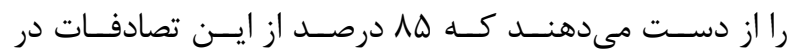

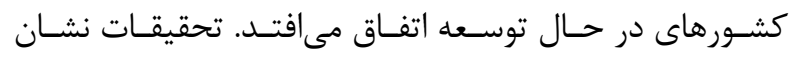

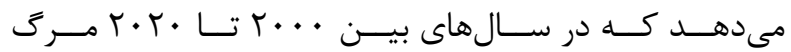

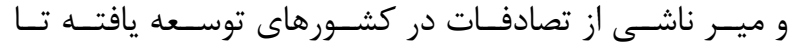

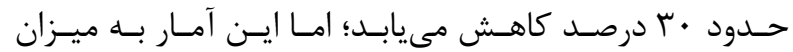

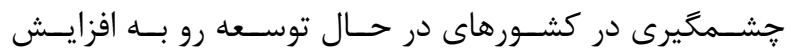

خواهـد بـود.

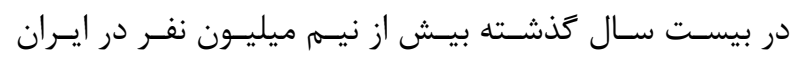

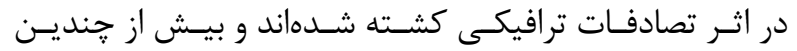

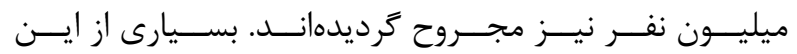

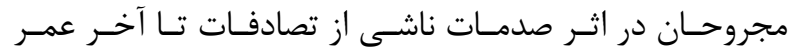

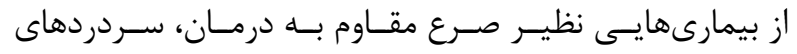

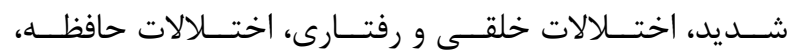

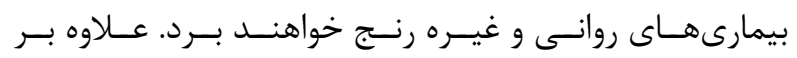

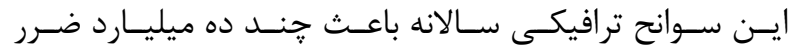

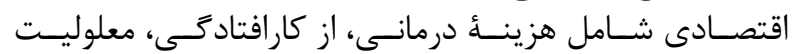

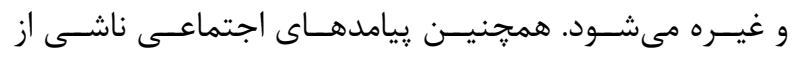

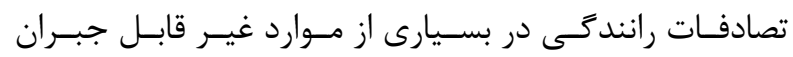

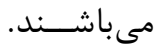

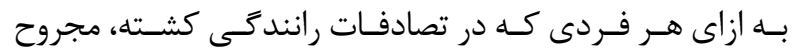

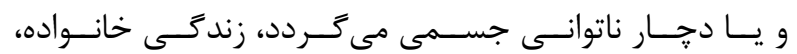

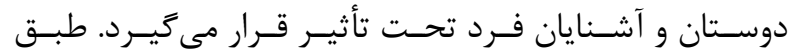

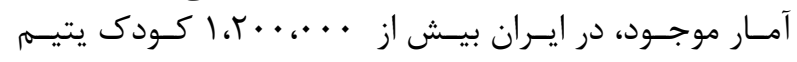

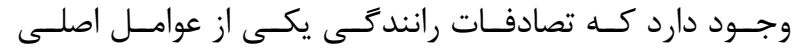

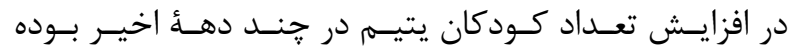

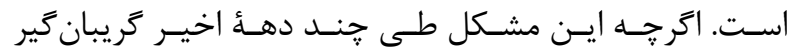

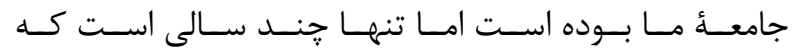

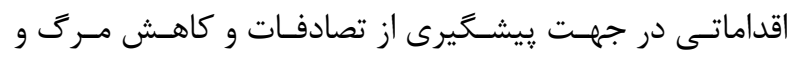

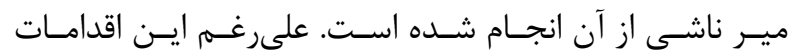

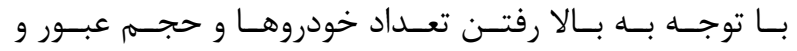

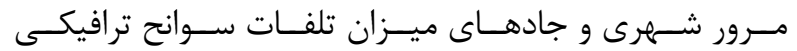

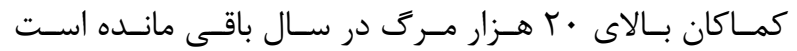

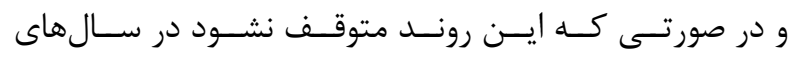

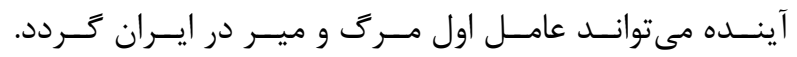

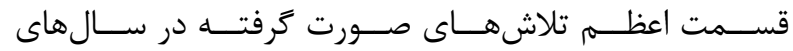

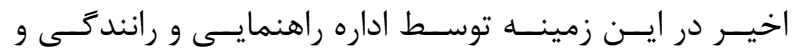

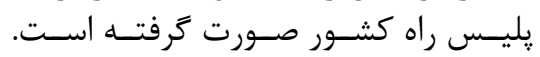

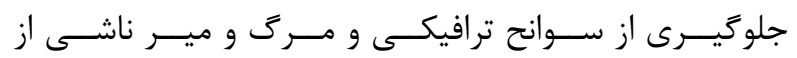

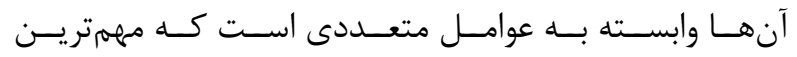

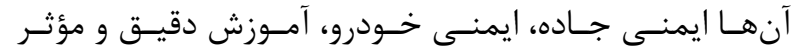

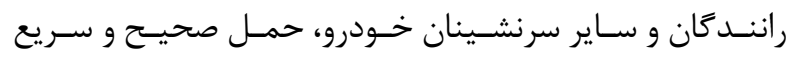

${ }^{3}$ Unicef

${ }^{4}$ International road traffic and accident database

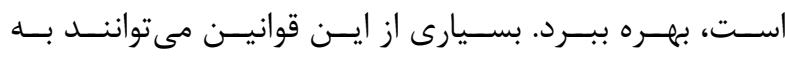

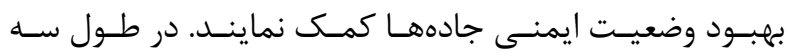

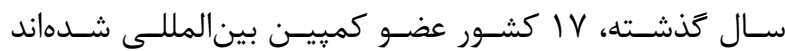

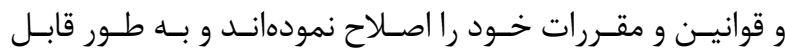

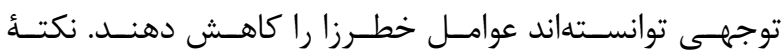

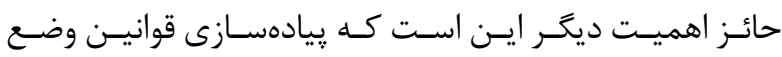

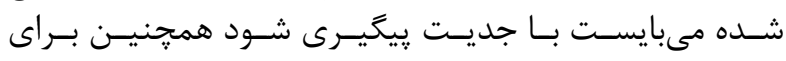

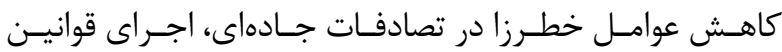

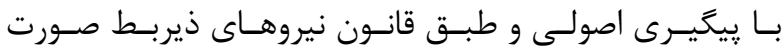

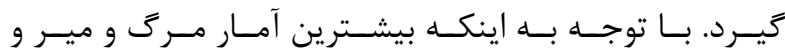

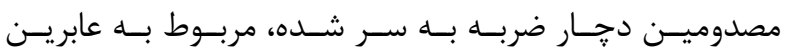

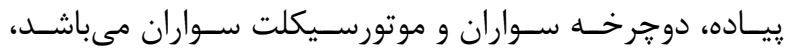

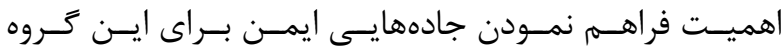

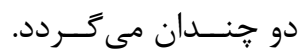

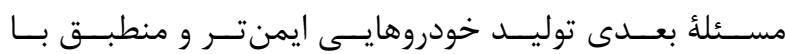

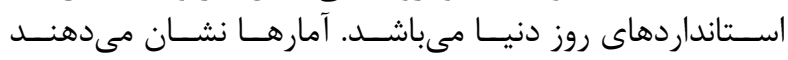

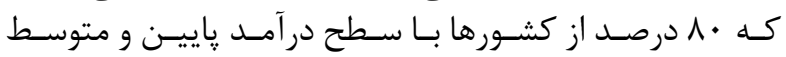

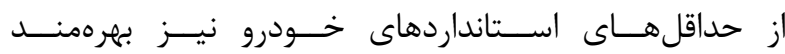

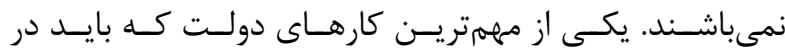

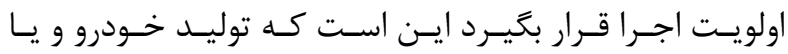

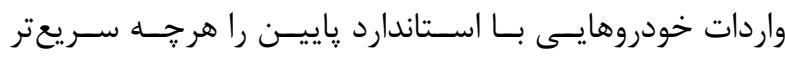
متوقـف نماينــد (V)

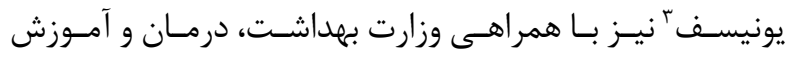

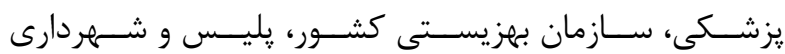

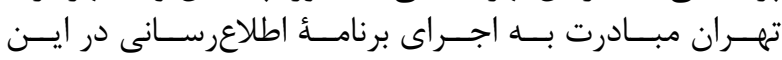

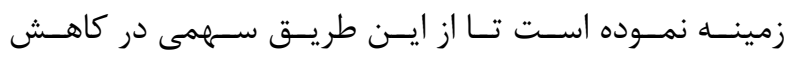

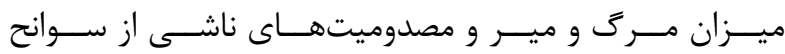

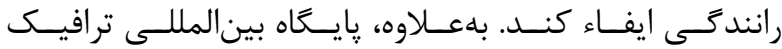

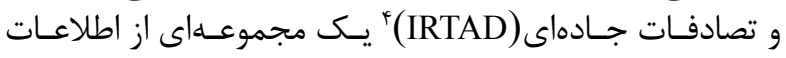

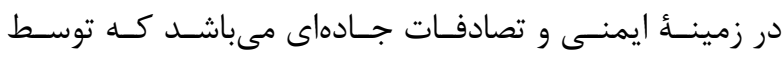

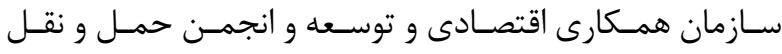

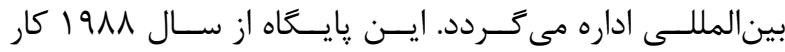

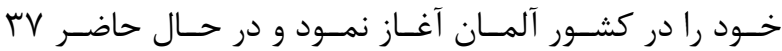

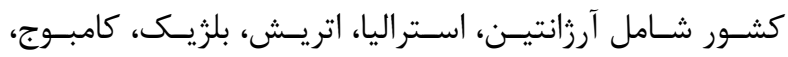

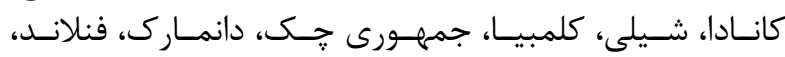

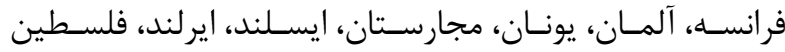

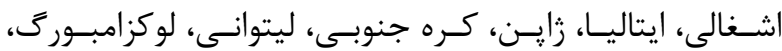

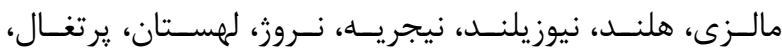

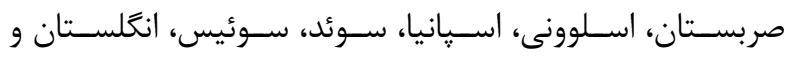

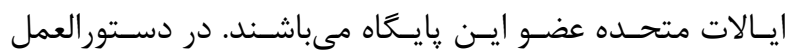

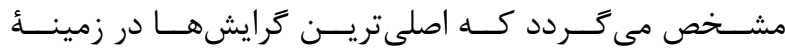

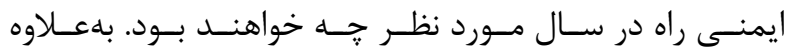

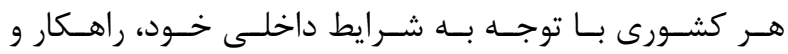

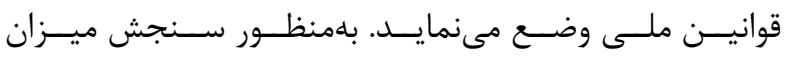

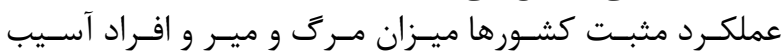

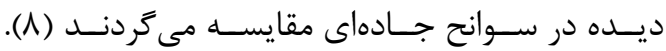




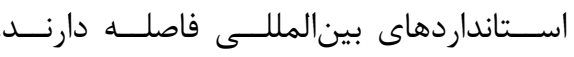

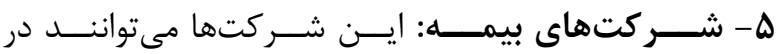

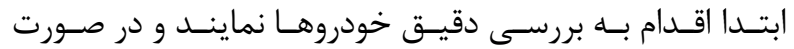

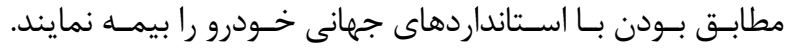

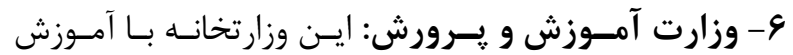

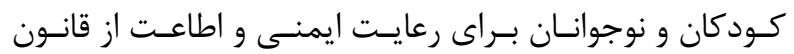

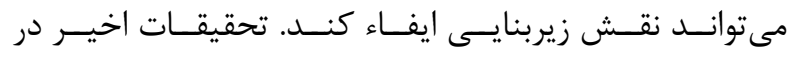

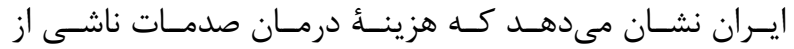

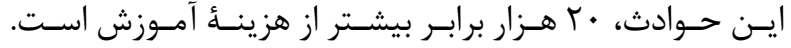

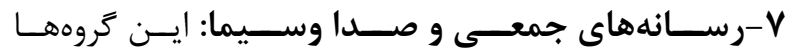

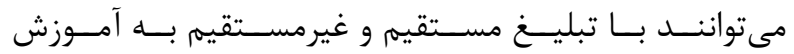

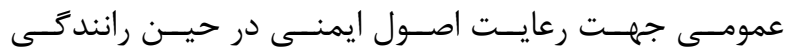
كمـك نماينــد.

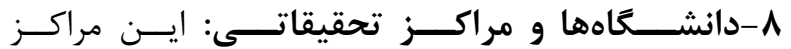

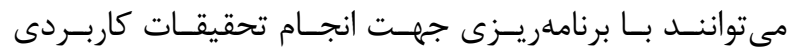

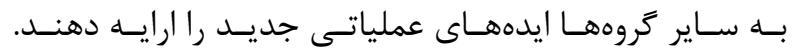

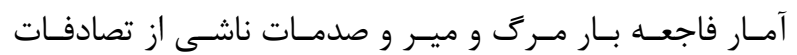

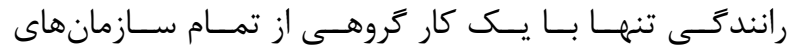

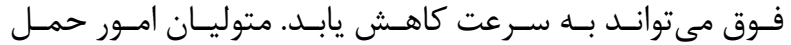

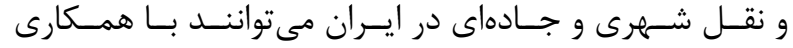

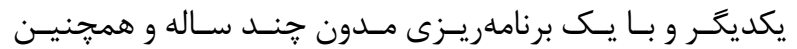

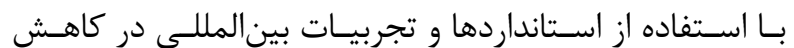

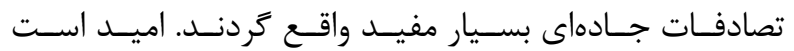

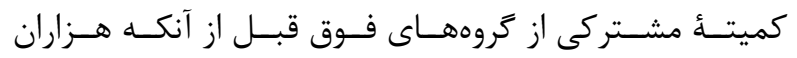

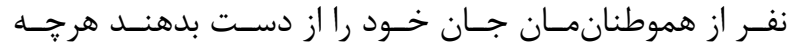

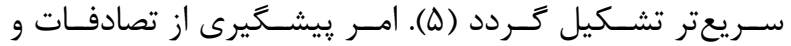

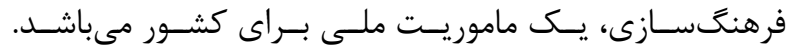

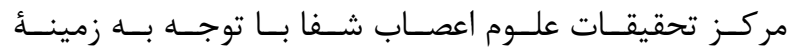

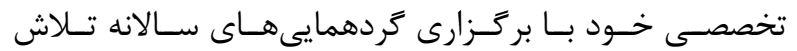

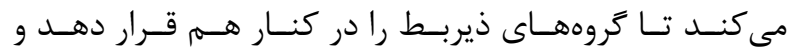

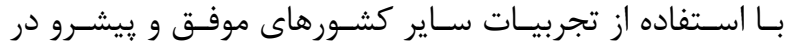

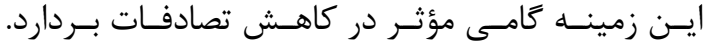

1. Global status report on road safety 2015. http://www. who.int/violence_injury_preventaion/road_safety_ status/2015/en/.

2. Wegman F, Hagenzieker MP. Editorial safety science special issue road safety management. Safety Science. 2010; 48(9): 1081-4.

3. Larsson P, Dekker S, Tingvall C. The need for a systems theory approach to road safety. Safety Science. 2010; 48(9): 1167-74.

4. Hoekstra T, Wegman F. Improving the effectiveness of road safety campaigns: current and new practices.

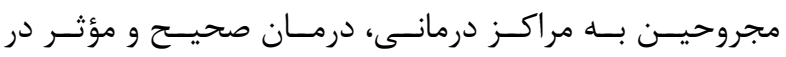

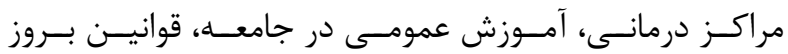

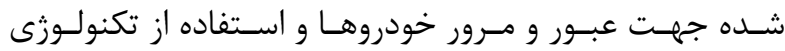

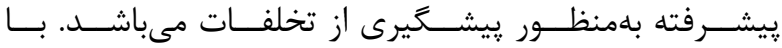

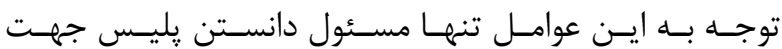

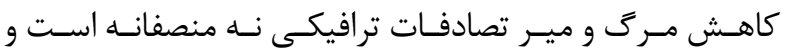

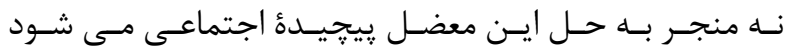

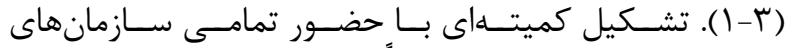

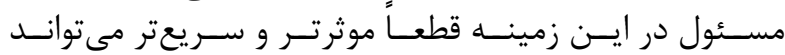

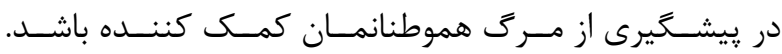

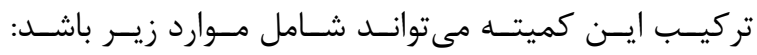

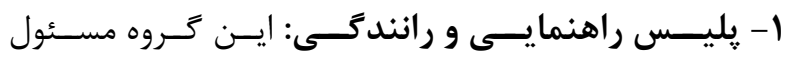

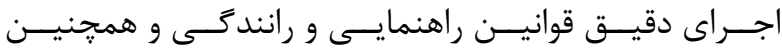

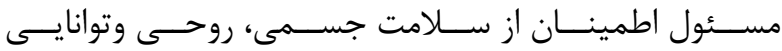

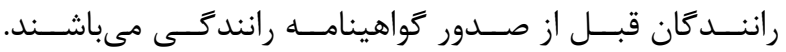

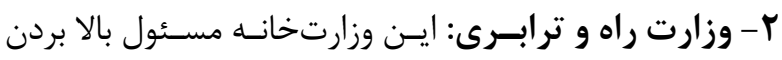

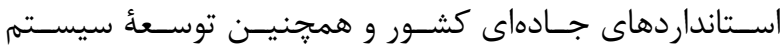

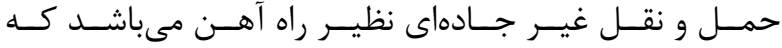

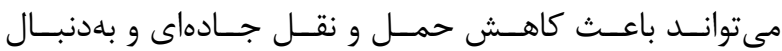
آن كاهـش تصادفـات كَردد.

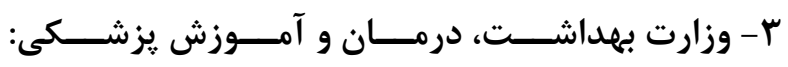

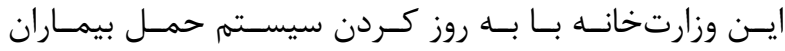

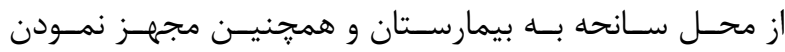

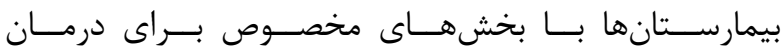

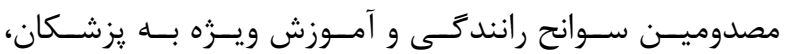

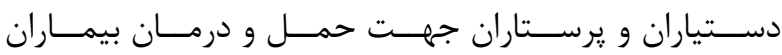

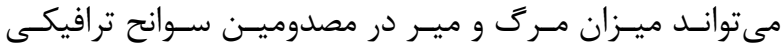

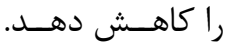

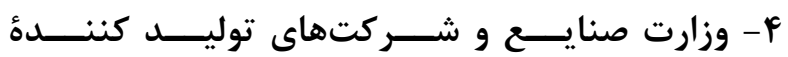

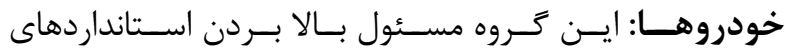

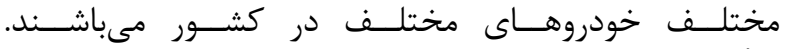

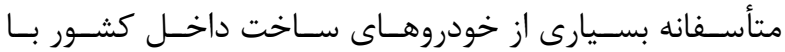

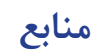

IATSS Research. 2011; 34(2): 80-86.

5. Gorji A. The first international congress of road safety in Mashhad, Iran. J Inj Violence Res. 2012; 4(2): 101-2.

6. Ansari M, Gorji A. Improvement of children road safety in Iran. Shefaye Khatam. 2016; 4(1): 93-6.

7. Toroyan T. Global status report on road safety. Inj Prev. 2009; 15: 286. doi:10.1136/ip.2009.023697.

8. International traffic safety data and analysis group (IRTAD). http://www.itf-oecd.org/IRTAD. 